Journal of Information Systems Engineering \& Management, 2:1 (2017), 5

ISSN: 2468-4376

\title{
Evaluating Youtube Platform Usability by People with Intellectual Disabilities (A User Experience Case Study Performed in a Six-Month Period)
}

\author{
Tânia Rocha ${ }^{1 *}$, José Martins ${ }^{1}$, Frederico Branco ${ }^{1}$, Ramiro Gonçalves ${ }^{1}$ \\ ${ }^{1}$ University of Trás-os-Montes e Alto Douro and INESC TEC, PORTUGAL
}

*Corresponding Author: trocha@utad.pt

Citation: Rocha, T., Martins, J., Branco, F. and Gonçalves, R. (2017) Evaluating Youtube Platform Usability by People with Intellectual Disabilities (A User Experience Case Study Performed in a Six-Month Period), Journal of Information Systems Engineering \& Management, 2:1 (2017), 5.

doi: http://dx.doi.org/10.20897/jisem.201705

Published: January 5, 2017

\begin{abstract}
A comparison study of the Web interaction evolution of a group of people with intellectual disabilities, when performing search tasks using the YouTube platform, is presented. For the effect, we compare results in two assessment moments (the second assessment moment was performed, within the 6 months after the first one).

We aimed at evaluating the evolution of their digital skills by comparing two assessment moments through the following usability variables: effectiveness, we register the rate of successful complete conclusion of Web search activities using the YouTube; efficiency, where it was register: time of task conclusion, number and type of difficulties found and errors made; satisfaction, the rate of acceptance and comfort when performing the tasks; and, autonomy indicators.

The results revealed that participants depicted more learning skills when performing the second assessment moment, which is indicated by the number of participants who were able to conclude the activities and it's also confirmed by the prominent results of the second assessment moment. When it comes to errors, they made more errors in the first assessment moment in general. While handling the input devices the participants had a better performance with the mouse than the keyboard however in the second assessment moment they improved their skills with the mouse and keyboard input device. However, we believed that the keyboard will never be a device that they can be autonomous with due to their reading/ writing difficulties, which itself represents a didactic challenge when it comes to the very presentation of appropriate methodologies and techniques that may help them overcome such problem. Overall, users with intellectual disabilities had a good experience with the YouTube interface because they were motivated and satisfied during the execution of the tasks, however they were not autonomy with the search option.
\end{abstract}

Keywords: digital literacy, intellectual disability, learning disabilities, web interaction, YouTube platform

\section{INTRODUCTION}

Knowing that the group of people with intellectual disabilities has great motivation to interact with digital environments (Rocha, 2008), but also shows great interest in interacting with images as these help them to perform online universal tasks successfully, such as: selection, manipulation and navigation (Rocha et al., 2012), it is intended to study how this public interacts with an audio-visual content platform (therefore of greatest interest to them).

We aim at studying on how a group of people with intellectual disabilities, access Web content being individuals that they based on a difficult interaction metaphor that is the inclusion of keywords which implies reading and 
writing skills, abilities conditioned due to their own disability characteristics (Rocha, 2014). After this first aim we intend to compare: Is this group can gather web search abilities in a six period of learning?

In this context, a case study is presented that aims to evaluate interaction and usability of the YouTube platform, in terms of effectiveness (success or failure in conducting research), efficiency (average times for the realization of tasks, number of errors and difficulties observed), satisfaction (taste and desire to repeat the task), and also autonomy (time they spend interacting autonomously with YouTube searching contents of their preferences). But the comparison of their learning skills based on the accessibility of the interface.

Our motivation to accomplish this study was born by the awareness caused by the lack of scientific data on how to make Web content accessible for people with intellectual disabilities, by verifying this is an undeveloped area and hard to standardize, mainly due to the different conditions found in the group of people with intellectual disability. Also, the consciousness of the importance of technology in people's life, the need to provide usable and accessible platforms and to teach how digital excluded groups can handle technology, was very important to us. We intent not only to record the conditions, the way they do and react, but to have the opportunity to really be a part of something that they are being denied, opening the range of accessibility, digital usability and fighting for a "digital world" is really inclusive.

\section{BACKGROUND}

For Internet users, who have disabilities, can overcome the obstacles inherent in navigation in the various websites available, it is expected that these pages are developed in accordance with international accessibility and usability standards. However, as shown by the studies presented by various authors (Gonçalves, Martins, \& Branco, 2014), the majority of Web sites available to the public do not meet the minimum requirements of accessibility or usability standards.

Although it may seem distinct concepts, accessibility and usability are closely related. You can consider accessibility (associated with the world of ICT) as a tool to simplify how a set of features can be used and how, consequently, the productivity resulting of the user experience is also increased (Amstel, 2005). Usability is the measure by which a product or environment can be used by a particular group of users to achieve specific goals with level of effectiveness, efficiency and satisfaction of a product or environment for a particular group of users (ISO, 1997). Through the application of these concepts, it would be allowed end users to learn simpler and faster on how to use a product or service and therefore made fewer errors in their interaction (Rocha, Carvalho, Bessa, Reis, \& Magalhães, 2016).

Thus, these concepts should be considered when it is indicated, in several national and international studies, that the computer and other technologies usage have major advantages in the learning process. So these technologies must be developed according to accessibility and usability guidelines to include all people regardless their physical or intellectual abilities.

The use of Information and Communication Technologies (ICT) is responsible to provide new ways to transmit knowledge, several possibilities of communication, motivational tools to enhance learning, access, efficiency and quality of the learning process (Ribeiro, Almeida, \& Moreira, 2010). So they lead to increase motivation, performance and promotion of its users (Balanskat, Blamire, \& Kefala, 2006; BECTA, 2007; Gutterman, Rahman, Supelano, Thies, \& Yang, 2009; IICD, 2007).

Several studies recognize the advantages of the ICT usage with students with disabilities due to the user's motivation in the interaction with the computer, used as assistive technology or pedagogical tool (Balanskat et al., 2006; BECTA, 2007; Kirinić, Vidaček-Hainš, \& Kovačić, 2009; Ribeiro, Moreira, \& Almeida, 2009). Also, it highlighted the importance of additional research on users-interface interaction, accessibility of contents, pedagogical approaches using ICT to support inclusion in special needs of education (BECTA, 2003).

Specifically, for people with intellectual and learning disabilities, the number of ICT solutions developed is low (Williams, Jamali, \& Nicholas, 2006). Within this group of people, they face several accessibility and usability barriers, raised by their own disability, leading to digital exclusion of these users (Rocha et al., 2012), such as: slow learning, low reading comprehension, limited fine motor control, reduced spatial perception, low visual acuity, less hand/eye coordination, finger dexterity and lowered information overload thresholds) (Friedman \& Bryen, 2007).

Within this context, the research team started to work with a group of people with intellectual disabilities that presented many educational/didactic challenges as they had many difficulties to be motivated to perform school activities and presented many unfinished tasks. This challenge leads us to study accessibility and usability of Web resources and to present how the Web can be a viable option to enhance learning for this group of people.

The present study emerges from previous work (Rocha, Martins, Gonçalves, \& Branco, 2016) that was developed with the goal of studying the interaction with the YouTube platform because we have seen that the group with intellectual disabilities payed attention when using video and images platform. As the YouTube platform is an excellent platform with several video contents, content of interest for this group, it is presented in 
this paper that a study on usability, aiming to observe how a group with intellectual disabilities perform search tasks with the YouTube Platform. To assess their learning skills, it is presented in two assessment moments to compare and analyses their abilities to learn and to develop their digital skills. For that, we invited a group of people with intellectual disability to interact with the platform. The very same evaluation with similar tasks were repeated, after a six-month period, to measure their progress regarding their digital skills on performing these tasks with the You'Tube platform.

\section{CHARACTERIZATION OF THE PARTICIPANTS}

Twenty participants took part in this study ( 8 women and 12 men): age range between 22 and 44 years old. These participants were selected by a special education teacher and a psychologist, according to the level of literacy, ranging primary education (1st and 2 nd year), more specifically, 15 in the first year and 5 in the second year. Five individuals could read and write, twelve could write only the name and three could not read or write. It should be noted that all these participants cooperate in an Occupational Activities Centre (CAO) of a national private school.

After seven years of being part of a previous project of digital integration, we can say that the group has presented the same level of experience in interacting with digital environments, i.e., using the computer with the traditional input devices (mouse and keyboard) and the Internet (Rocha, 2014). Specifically, twelve participants used the computers over two times during the week and eight used only one time a week.

Regarding their intellectual disabilities, the individuals were not associated to only one pathology, but a group of pathologies (for example, fetal alcohol syndrome with dysgraphia). According to DSM-V, these pathologies can be classified according to severity levels, between mild to moderate, but only one of the participants presented a high level of disability (APA, 2013). Also within the group, twelve participants had normal vision and six have corrected to normal vision. None of the participants has any motor disability or fine motor problems (no problems in handling the pencil / marker, mouse).

All participants were volunteers and had permission from their legal guardians or tutors to participate in the study. However, if there was any sign of discomfort or frustration the activity was immediately suspended.

\section{CASE STUDY}

In this case study, we assessed the user interaction and usability of the YouTube platform. Participants were invited to interact in a real situation of search, using the usual search field through keywords, to register their level of performance and autonomy. Therefore, we aimed at assessing their learning process evolution with the YouTube platform by registering their interaction in a period of six months.

\section{Methods}

In this study, the case study (Yin, 2013) and ethnography (Knoblauch, 2005) are allied with the usability evaluation (through user tests) (ISO, 1998). We observed and took notes of the difficulties felt in their interaction and also of their potentially technological skills (how they can manage to complete successfully digital activities using the usual input devices). We also took notes of the errors made when using the Web and compared all the results between the two interaction periods.

The data collection methods used are directly related to the methodological approach adopted and includes: record books, document analysis, interviews, direct observation, user testing, effectiveness, efficiency and satisfaction variables.

\section{Experimental Design}

The YouTube platform was chosen mainly for return search results, i.e., videos, previously considered of great interest to the target group of the study (Rocha, 2014). Choosing interesting learning activities to perform, appealing web content or platforms to interact is considered very important to keep the group motivated. So, to gather their attention and motivation to perform understandable, interesting and interactive tasks with the YouTube platform, we chose search tasks directly related to their favourite daily activities such as: music, sports, games and cinema.

These tasks were chosen in order to: motivate the group to perform the tasks in digital environments; enhance their abilities when performing search tasks in the YouTube platform; and training of the use of the mouse and keyboard input devices. All tasks performed in the two assessment phases had the same difficulty level aiming to assess their apprentice level regarding the mouse and keyboard handling and success when it came to reaching the expected search goal.

In the two assessment moments, they add to perform four search tasks: 


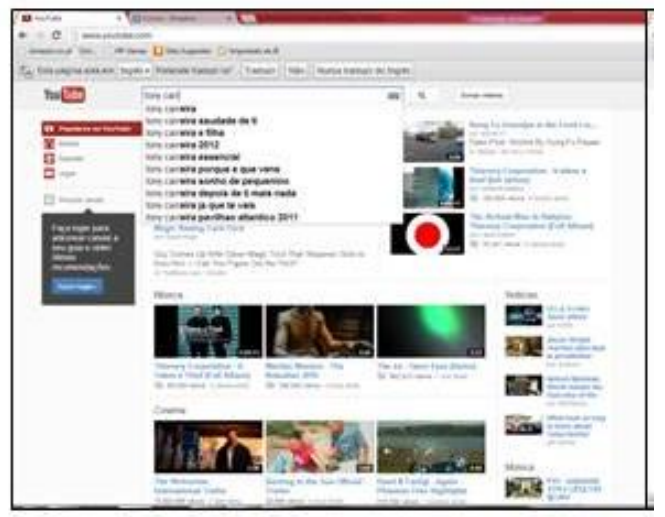

Figure 1. Web screen of the first step for all tasks

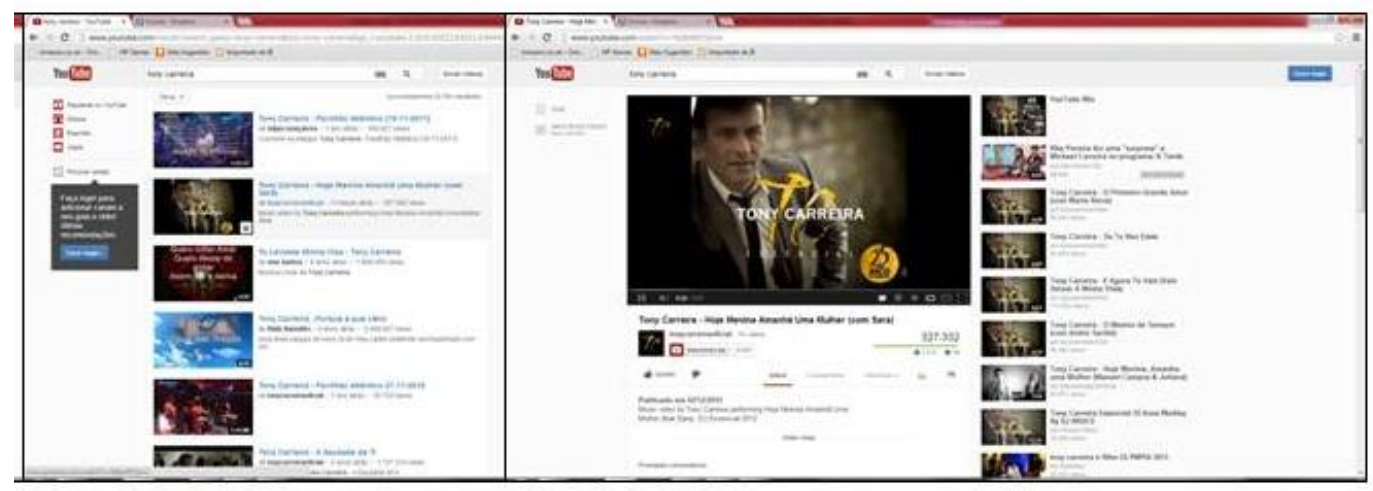

Figure 2. YouTube web screens of the Music Web Search (T1)

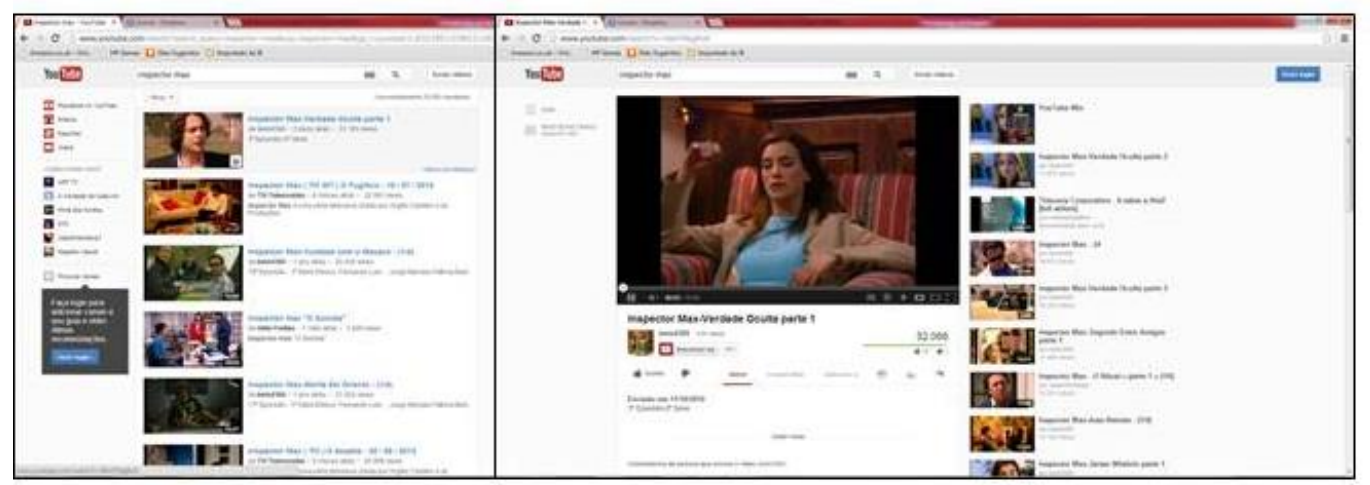

Figure 3. YouTube Web screens of the TV Series Web Search (T2)

- Task 1 (T1): search one music of Tony Carreira (Portuguese singer) on YouTube platform.

- Task 2 (T2): search one episode of the Inspector Max (TV series) on YouTube platform.

- Task 3 (T3): search one Portugal football team match on YouTube platform.

- Task 4 (T4): search one card game on YouTube platform.

Next, we present images that can be examples of the interaction asked for the successful completion of four training tasks defined above. Figure 1 shows the first step for all tasks (enter the Keyword in the search field).

The layouts for the first task (T1), second task (T2), third tastk (T3), and fourth task (T4) are presented in Figure 2, Figure 3, Figure 4, and Figure 5, respectively.

The success criteria were toward the conclusion of the task; defined according to the steps to perform the tasks, those were: the users needed to write the keyword correspondent to the task that was being performed, then press enter or click in the search icon next to the search field. To conclude the task, participant had to click in a video matching the web search asked previously. The task is given as not completed successfully if user clicks on a video that does not match the defined tasks initially.

Concerning to the evaluation criteria, we used the variables defined as those associated with the usability assessment process (effectiveness, efficiency and satisfaction) as a way to check the user experience and performance. For effectiveness, it was recorded how many users completed the tasks successfully without giving 


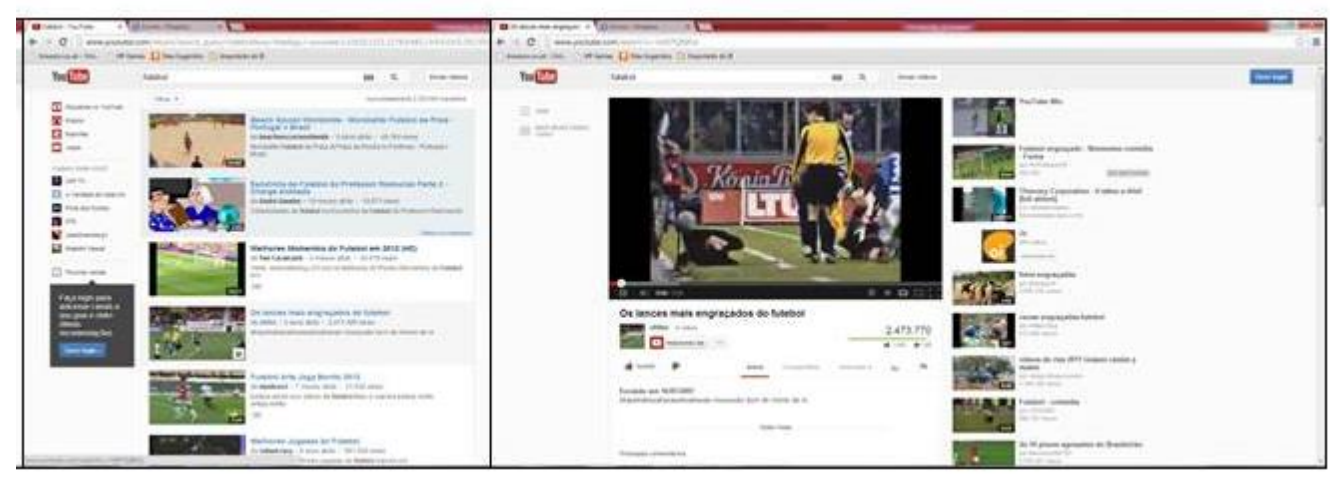

Figure 4. YouTube Web screens of the Football match Game Web Search (T3)

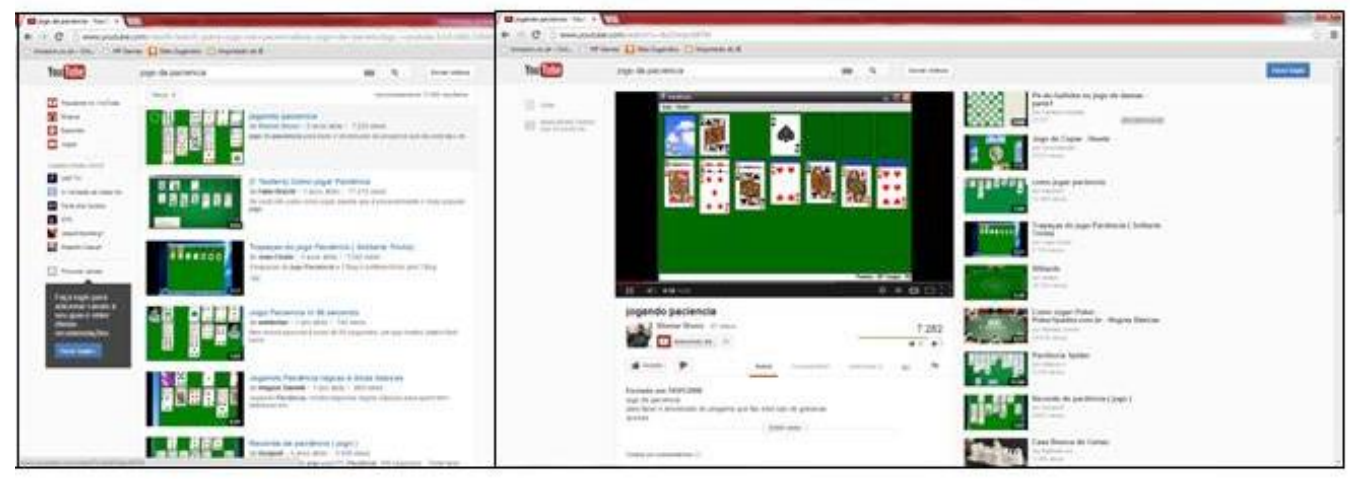

Figure 5. YouTube Web screens of the Football match Game Web Search (T4)

up. In efficiency, they considered the resources used to achieve effectiveness: time to complete the task, errors made during the interaction (specifically: clicking on links unrelated to the tasks, click repeatedly in a given area background or coloured areas - and confusion with mouse buttons), and other difficulties encountered during the experiment, such as low precision to click on small areas, poor understanding of the tasks and the weak interaction with touch devices. To register user satisfaction, we found that participants showed themselves comfortable when carrying out the tasks or asked to repeat some or all tasks.

\section{Procedures}

The first assessment phase lasted for four weeks, approximately 35 hours in total, and a half hour per individual. The second assessment lasted for four weeks: to perform the tasks asked (one weeks, approximately 5 hours in total and a quarter hour per individual), autonomy ( +3 weeks, +20 hours +15 minutes per participant. During the six-month period the group faced another Web tasks and performed other activities using the mouse and keyboard device.

Before starting the tests, it was explained to the users what was intended with each task. Then they were invited to sit in front of the computer and eye tracking device to a distance no greater than 1.5 meters. They use the Chrome browser and the YouTube platform was already open. To start the search, the observer/evaluator wrote the keyword on a sheet and the user must have had to reply the characters with the keyboard. Subsequently, the user had to click on the magnifying glass icon to start the search. Finally, the task was considered over, after the user clicked on a video that corresponds to the option chosen at the beginning of the task. The tasks were performed randomly.

\section{Apparatus}

The material resources used in this case study were: a computer (Asus X552C), keyboard (QWERTY), optical mouse (Logitech M100), a NEC monitor with $54.6 \mathrm{~cm}$ (21.5 ") also paper and pen to assist users in keyword searching replication. An eye tracking device was used to manage and obtain registration of how the individual see for a particular image / scene / interface in order to make the reading position and eye movement. With the use of this device, it was intended to check WHERE the user looks in real time and which area he/she focused (Jacob, 1995). This process results on the recording of the scene in question, where the user focuses his attention is taken into account how long the user focuses on particular scene and the ORDER in which follows. 


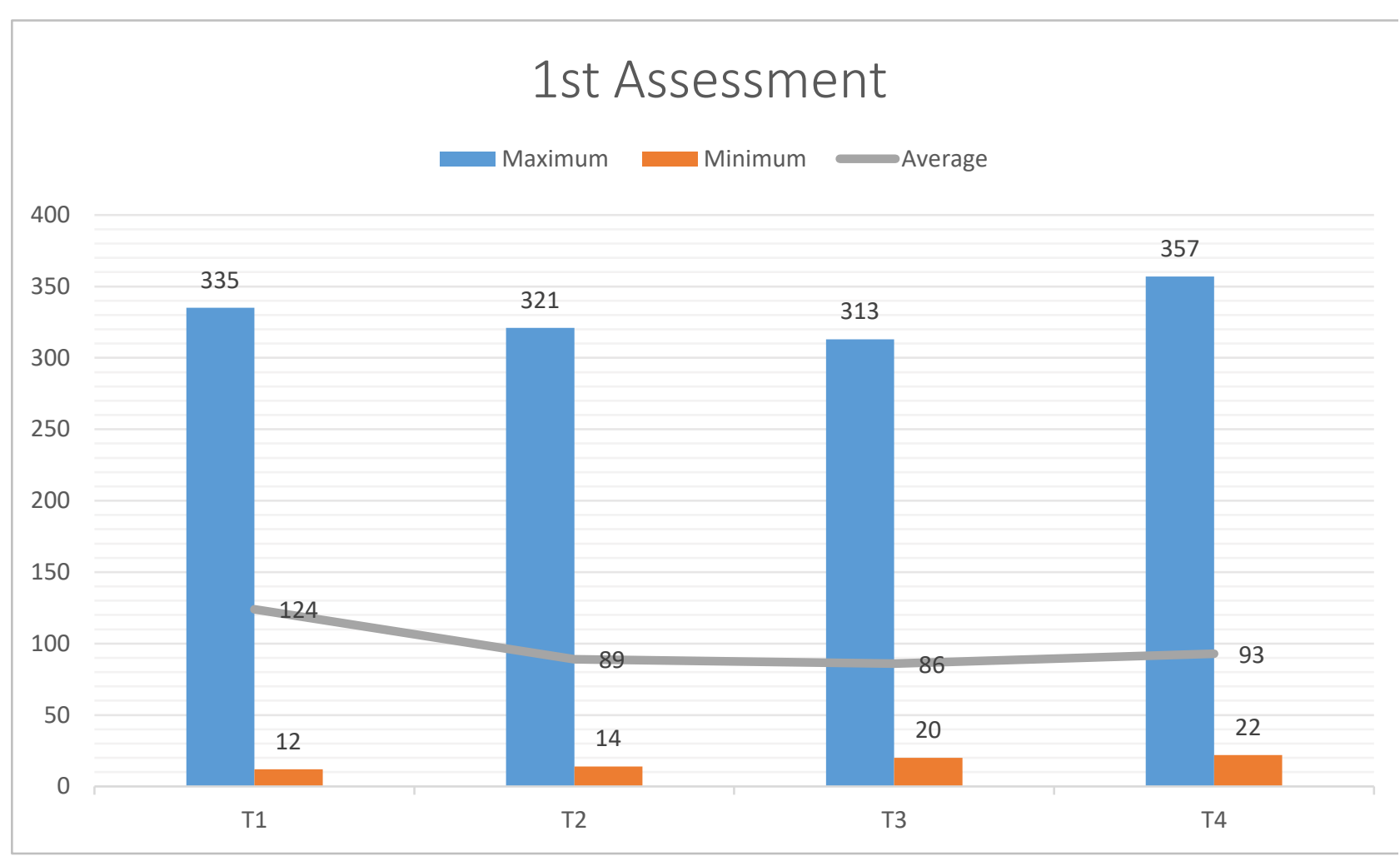

Figure 6. Minimum, Maximum and Average Time for the first assessment

\section{RESULTS}

The results presented in this section are focused on the comparison between the first and second phase of assessment.

Regarding effectiveness, in the first assessment phase, the successful completion of four tasks and satisfaction was $100 \%$. No participant dropped out and all showed willingness to continue activity after completion of the four tasks. However, no one actually performed an extra task. In the second assessment phase, the successful completion of four tasks and satisfaction was also 100\%. No participant was dropped out. Six participants carry out one extra Web search, fourteen users performed more than two extra Web searches.

As regards efficiency, is presented firstly, the average time to conclude the tasks, obtained in the two assessment phases (Figures 6 and 7).

Specifically, in the first assessment moment, first task (T1) users took, on average, about 124 seconds to complete the task. ID 16 had the slowest performance of 335 seconds, and the fastest was ID 12 that finished the task in 12 seconds. In the second task (T2), the average time was 89 seconds. The slowest participant (ID 16) recorded 321 seconds and the fastest, ID 15, finished the task in 14 seconds. In the third task (T3) the average time was of 86 seconds. ID 13 presented the slowest performance of 313 seconds and the ID 15, the fastest, 20 seconds. In the last task (T4), the average time was 93 seconds. ID 13 had the slowest performance, 357 seconds, on the other hand, ID 14 presented the fastest performance of 22 seconds.

In the second assessment moment, first task (T1) users took, on average, about 105 seconds to complete the task. ID 7 had the slowest performance of 227 seconds and the fastest was ID 14 that finished the task in 10 seconds. In the second task (T2), the average time was 81 seconds. The slowest participant (ID 13) recorded 160 seconds and the fastest, ID 12, finished the task in 15 seconds. In the third task (T3) the average time was of 79 seconds. ID 13 presented the slowest performance of 148 seconds and the ID 12, the fastest, 16 seconds. In the last task (T4), the average time was 56 seconds. ID 6 had the slowest performance, 88 seconds, on the other hand, ID 1 presented the fastest performance of 19 seconds.

Regarding the total number of errors made, in the first assessment moment, in the four tasks, it was registered a total of 47 errors. These errors were related to: the replication of the characters and writing of keyword on the searching field (21 errors made); the mouse handling, as they confused the left and right function buttons (8); the keyboard handling as they were confused with the function keys, such as use "Enter" to delete a character, or clicked continuously on a key (18). 


\section{2nd Assessment}

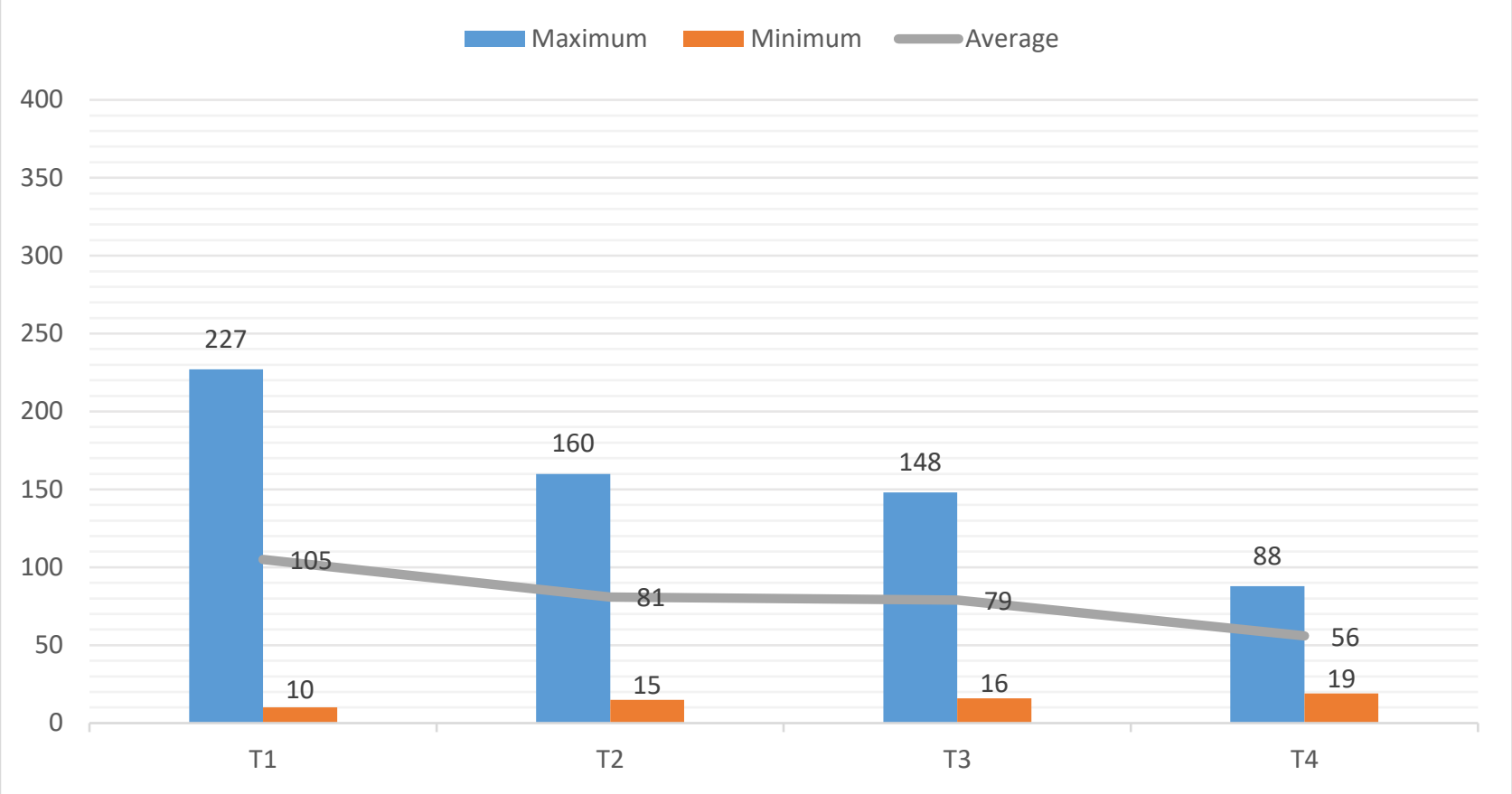

Figure 7. Minimum, Maximum and Average time for the second assessment

In the second assessment moment, in the four tasks, it was register a total of 31 errors made. The errors observed were almost all concerning the replication of the keyword with the keyboard. All of them overtook the mouse and keyboard handling difficulties.

Another assessment variable register was the difficulties users experienced in carrying out the task. In the first assessment moment, ID 1, ID 4 and ID 6 had many difficulties with the mouse handling (which they overcome in the third task), ID 7, ID 8, ID 13 and ID 16 (improved in the second task). This difficulty was observed on the video manipulation buttons and the YouTube icons, because the small sizes of the icons implied precision on clicking and the design was very abstract they had many difficulties to understand and identifying these icons functions. Also, difficulties on the keyboard handling was observed in the tasks performed by ID 1, ID 3 and ID 5 (that improved over the course of the task 1), ID 7 (improved in the second task), ID 9 (in the task 3) and ID 13, ID 16, ID 19 and ID 20 (that improved in the fourth task). The recognition, writing and replication of the keyword characters in the search field was another difficulty observed. Users identified as ID 5, ID 6, ID 10 and ID11 improved their performance over the course of the task 2. ID 15 and ID18 failed to overcome this difficulty without help. Only one user (ID 1) had difficulties in understanding of the task, however, he/she overcame the difficulties in the third task.

In the second assessment moment, participants did not show difficulties in the mouse and keyboard handling, however it is clear that they cannot be autonomous with the second input device, because each time they had to write the keyword they asked for help. We believe that this search metaphor is not appropriate to this group of people because of their own disability, this cannot give them autonomy to freely perform a search task.

Regarding the difficulties observed on video manipulation buttons, they showed a previous learning on how they could maximize, minimize and close the video window and also showed learning abilities with the stop, pause and play options of the video.

With the results of eye tracking device, it can be observed as an important aspect of the interaction. All users ignored the left navigation menu represented by icons. It seems that the small size of the icons helps the menu to go unnoticed. Even those who have used this platform did not recognize this form of search. Verifying this indifference, at the end of the tests, the observer / evaluator called attention to this navigation option. However, users continued to ignore it, in the following search tasks, they preferred to head swiftly to the search field to start the search by keyword.

Another important feature was that user quickly recognized the search field and knew that to perform a search they must enter information in that top space, the search field, to start the search. The largest recorded problem is that much of this public, including this group in particular, have low levels of literacy, compromising the writing 
ability and reading, thus requiring research assistance. For this reason, it is foreseen that will never be completely autonomous, in the search function keyword insertion.

To conclude this analysis, it is registered that some interaction problems with the user interface aiming to record barriers of access into YouTube platform for the specific group here we study.

First, the left side navigation menu represented by icons is totally ignored by users and disappears after being used in the first task. Thus, in a second task the user cannot use this function because the menu disappears. To view this navigation menu option again it is necessary to close the page and re-open it. In the case of a registered user, the same thing happens, the menu disappears; the user must exit from their account to view the menu again. This issue listed was observed in the two assessment moments.

Second problem encountered is that the presentation of results is made without regard to the users' spoken language. For this particular target audience face problem because users got confused, not knowing whether the task was successfully completed if the video as other language that they do not recognize. This problem is more prevalent in task 2, where they search for a TV series. This issue listed was observed in the two assessment moments.

Third, also the sound content of the video is not standardized by any parameter, this causes the tinkering in sound volume, leading to another serious problem of the need for mouse click accuracy as the button is of small size and you need to click and drag to increase the volume. The video manipulation buttons had the same problem, small dimension considered for the proper functioning / handling of video was a challenge for this group of people. This issue was overcome in the second assessment moment. Users showed their learning abilities, as they recognized the icons to execute the volume option and improve their digital skill.

Fourth, it was also noted that the advertising presented in the beginning of the videos imposes fatigue and frustration and several participants commented, "how boring this was."

Fifth, finally, most users did not use the scroll of the mouse input device nor the browser, therefore they did not see all the videos presented at the end of the displayed page, thus not representing an ideal solution to show more content for this group of participants.

\section{LIMITATIONS}

In this paper, we sought to understand how a group of people with intellectual disabilities interact with the YouTube platform by using the search by keyword feature. Only this feature is assessed even though we register several interaction problems raised by the interface while their interaction. We believe that is important to run a complete accessibility and usability study on this platform because of its unique and important content for people with intellectual disabilities.

One limitation of the study is that we do not use a control group (with or without disabilities) to compare usability results. Another limitation of this study is the number of participants, we intend to increase this number to verify if the interaction problems are the same, also to perform more and different Web search tasks.

\section{CONCLUSION AND FUTURE WORK}

In conclusion, after performing the evaluation of usability on the YouTube platform and after analysing performance, satisfaction and problems encountered in the interaction, when the research action, it appears that the platform does not allow an autonomous interaction for people with intellectual disabilities.

Although the dropout rate is inexistent in the two assessment moments, the need of search for specific content using the search field by entering keywords is not an effective option for the group of people with intellectual disabilities due to their own disability, i.e., the difficulties in reading and writing skills. After the two assessment moments, it was observed that after the first iteration, users prefer to navigate by clicking content in content, then to return to the search field. Also, they totally ignore the left side navigation menu represented by icons even when they had much experience with the platform.

In relation to the interaction with the user interface, it was found many interaction problems that confused and demotivated users to complete tasks in the platform, such as: the results presentation made without any regard to the language of the user; presenting advertising with the videos; the sound content of the videos was not standardized by any parameter, and this issue decreased the concentration of the task because user is always trying to resolve the situation and not focused on the completion of the task leading to major time to complete the task; and finally, the small size icons dimensions presented to manipulated videos. However, despite of these interaction problems that are difficult the access, the group showed great satisfaction by interacting in digital environments, especially those that provide easy to interpret content (movies). 
As future work, we intend to study other entertainment platforms and compare results as well as increase the number of participants, involving other groups such as children and the elderly.

\section{REFERENCES}

Amstel, F. (2005). What is usability?. Retrieved from http://usabilidoido.com.br/afinal_o_que_e_usabilidade.html APA. (2013). DSM-V- The diagnostic and statistical manual of mental disorders, 5th ed., Retrieved from http://www.dsm5.org/Pages/Default.aspx

Balanskat, A., Blamire, R. and Kefala, S. (2006). The ICT Impact Report: A review of Studies of ICT impact. European Schoolnet. Retrieved from http://ec.europa.eu/education/doc/reports/doc/ictimpact.pdf

BECTA (2003). What the research says about ICT supporting special educational needs (SEN) and Inclusion. (Coventry: Becta, 2003). Retrieved from http://www.mmiweb.org.uk/publications/ict/Research_SEN.pdf

BECTA (2007). The impact of ICT in Schools: Landscape Review. (Coventry: Becta, 2007). Retrieved from http://dera.ioe.ac.uk/1627/

Friedman, M.G. and Bryen, D.N. (2007) Web accessibility design recommendations for people with cognitive disabilities, Technology and Disability, 19(4), pp. 205-212.

Gonçalves, R., Martins, J. and Branco, F. (2014) A Review on the Portuguese Enterprises Web Accessibility Levels-A website accessibility high level improvement proposal, Procedia Computer Science, 27, pp. 176-185.

Gutterman, B., Rahman, S., Supelano, J., Thies, L. and Yang, M. (2009) Information Communication \& Technology (ICT) in Education for Development, Retrieved from http:/ / unpan1.un.org/intradoc/groups/public/documents/gaid/unpan034975.pdf

IICD (2007) ICTs for Education: Impact and Lessons Learned from IICD - Supported Activities. (The Hague: IICD, 2007). Retrieved from http://www.iicd.org/files/icts-for-education.pdf

ISO (1997) ISO 9241-11: Ergonomic requirements for office work with visual display terminals (VDTs), Part 11 Guidelines for specifying and measuring usability. Geneve.

ISO (1998) Ergonomic Requirements for Office Work with Visual Display Terminals (VDTs) - Part 11: Guidance on Usability - ISO 9241-11 (Vol. 2016).

Jacob, R.J.K. (1995) Eye tracking in advanced interface design, Virtual environments and advanced interface design, pp. $258-288$.

Kirinić, V., Vidaček-Hainš, V. and Kovačić, A. (2009) Computers in education of children with intellectual and related developmental disorders, International Journal of Emerging Technologies in Learning, 5(2), pp. 12-16.

Knoblauch, H. (2005). Focused ethnography. Paper presented at the Forum qualitative sozialforschung/forum: qualitative social research.

Ribeiro, J., Almeida, A.M. and Moreira, A. (2010) A utilização das TIC na Educação de Alunos com Necessidades Educativas Especiais: resultados da aplicação piloto do inquérito nacional a Coordenadores TIC/PTE, Indagatio Didactica, 2(1).

Ribeiro, J., Moreira, A. and Almeida, A.M. (2009) An approach to inclusion through information and communication technology, Paper presented at the Actas do I Congresso Internacional Família, Escola e Sociedade-Educação Especial, Educare, Porto.

Rocha, T. (2008) Accessibility and usability on the internet for people with intellectual disabilities. (Master Degree), University of Trás-os- Montes and Alto Douro, Vila Real, Portugal.

Rocha, T. (2014) Interaction metaphor for access to digital information an autonomous form for people with intellectual disabilities. (Ph. D Thesis), University of Trás-os-Montes and Alto Douro, Vila Real, Portugal.

Rocha, T., Besssa, M., Gonçalves, M., Cabral, L., Godinho, F., Peres, E., . . Chalmers, A. (2012) The recognition of web pages' hyperlinks by people with intellectual disabilities: an evaluation study, Journal of Applied Research in Intellectual Disabilities, 25(6), pp. 542-552.

Rocha, T., Carvalho, D., Bessa, M., Reis, S. and Magalhães, L. (2016) Usability evaluation of navigation tasks by people with intellectual disabilities: A Google and SAPO comparative study regarding different interaction modalities, Universal Access in the Information Society, pp. 1-12.

Rocha, T., Martins, J., Gonçalves, R. and Branco, F. (2016) Usability evaluation of an entertainment platform by people with intellectual disabilities, Paper presented at the Information Systems and Technologies (CISTI), 2016 11th Iberian Conference on.

Williams, P., Jamali, H.R. and Nicholas, D. (2006) Using ICT with people with special education needs: What the literature tells us, Paper presented at the Aslib Proceedings.

Yin, R.K. (2013) Case study research: Design and methods, Sage publications. 